\title{
E-mentoring as a Critical E-learning Approach: The Impact of Social Presence on E-mentoring
}

\author{
Ellen A. Ensher \\ Loyola Marymount University, College of Business Administration, One LMU Drive, Los Angeles, USA \\ Email: eensher@lmu.edu
}

Received May, 2013

\begin{abstract}
One important form of e-learning is e-mentoring. Virtual mentoring can occur within the context of formal organizational programs or develop spontaneously between individuals online. While e-mentoring is burgeoning as a practice, theoretical research related to this important phenomenon has been limited. The purpose of this paper is to suggest that social presence theory presents a useful conceptual framework for understanding mentors' willingness to participate in e-mentoring relationship and on their satisfaction. In sum, mentoring relationships that offer a blended approach with both high and low social presence forms of computer-mediated-communication (CMC) will be more satisfying to mentors than those with low social presence CMC forms only. Implications for research and practice are discussed.
\end{abstract}

Keywords: E-learning; E-mentoring; Learning; Mentoring; Social Presence Theory

\section{Introduction}

The two CEO's have a special relationship, with the two palling around together, Zuckerberg teaching Graham about Facebook and social media and Graham reciprocating with gems of wisdom about CEO life.

-Greenfield, Atlantic Monthly

Mentoring has morphed in recent years. Today's mentoring is a complex process with multiple permutations that depart from the traditional dyad in which a senior wise elder provides guidance to a novice (Clutterbuck, 2007)[1]. We now find that there is an array of different types of mentoring, such as the reciprocal mentoring relationship between Facebook's CEO Mark Zuckerberg, and Wash- ington Post's CEO, Donald Graham. Other types of new forms of mentoring include peer mentoring, group mentoring, and e-mentoring (Ensher \& Murphy, 2005)[2]. One of the most innovative forms of mentoring is e-mentoring, which is a mutually beneficial relationship between a mentor and a protégé which provides new learning as well as career and emotional support, primarily through email and other electronic methods (Ensher \& Murphy, 2007)[3].

E-mentoring is an important form of e-learning. It can occur within the context of a formal organizational program or informally through a spontaneously developed relationship between two individuals online. E-learning represents a 91 billion dollar market and is expected to continue to grow in future years (Farbey, 2013)[4]. Most e-learning products and platforms are targeted to a virtual classroom or group setting. However, professionals and students can also learn by developing a relationship with another person such as an e-mentoring relationship. In fact, e-mentoring is growing exponentially as a practice; however there is a dearth of rigorous research related to understanding overall factors impacting the effectiveness of e-mentoring in general, and mentors' willingness to engage in e-mentoring relationships in particular. The purpose of this paper is to suggest that social presence theory be used as a conceptual framework to understand mentors' willingness to engage in e-mentoring relationships and their overall satisfaction with the relationship. The impact of social presence on e-mentoring also has important implications for mentoring program design.

\section{Importance of E-Mentoring}

E-mentoring relationships are advantageous as they allow mentors and protégés to enjoy maximum flexibility as they communicate without the constraints of physical proximity or time (Ensher, Heun, \& Blanchard, 2003)[5]. Moreover, e-mentoring opens up avenues of mentoring for demographic groups such as for women and people of color that may be under-represented in certain careers and echelons and who may find it difficult to find faceto-face mentors (Single, Muller, Cunningham, Single \& Carlsen, 2005)[6]. Another advantage of e-mentoring is that the lack of visual cues decreases the distortion of precon- ceived notions or expectations based on demographics, thus providing a more level playing field 
(deJanasz, Ensher, \& Heun, 2008)[7].

Overall, e-mentoring is advantageous for all professionals as it provides an additional context that enables protégés to leverage the positive effects of multiple mentors that are crucial to career success (Higgins \& Kram, 2001)[8]. Due to the advantages of e-mentoring, there has been a rapid growth in these types of programs with businesses such as Triple Creek and Mentium providing platforms and support to companies such as KPMG who sponsor e-mentoring (An \& Lipscomb, 2010))[9]. One of the greatest challenges that mentoring program ad- ministrators face is the need to effectively recruit and match mentors and protégés (Headlam-Wells, Gosland, \& Craig, 2005)[10]. The purpose of this research is to better understand the importance of the impact of computer- mediated communication (CMC) on individuals' will- ingness to engage in mentoring, which has implications for matching and recruiting mentors and protégés.

\section{Theoretical Framework: Social Presence}

Social presence is the level in which social cues (e.g., tone of voice) are present in an interaction (Short, Williams, \& Christie, 1976)[11]. Face-to-face communication is considered the highest form of social presence and pro- vides a baseline for measurement (Harms, 2005)[12]. The high degree of social presence associated with face-to- face communication lies in the media richness of face- to-face interaction. Media richness describes the degree to which a medium can convey intended meanings of communication. In face-to-face communication, senders and recipients have not only the words but tone of voice, facial and body language to assist in understanding the meaning of the message. Each form of CMC is associated with different levels of social presence (Arbaugh, 2000)[13]; (Murphy, 2011)[14]. For example, Wang \& Newlin (2001)[15] found that synchronous technologies such as chat rooms provide a higher degree of social presence than asynchronous technologies. Feris, Gimeno, Pinazo, et al. (2002)[16] found that individuals that engage in chat room interaction do so in order to maximize their social inter- action. In addition, their study found that users of chat rooms perceived no difference in social presence be- tween face-to-face interaction or chat room interaction which bodes well for high social presence forms of CMC as a proxy for face-to-face communication. Furthermore, Murphy (2011)[14] found that blended mentoring in which e-mail plus talking on the phone or meeting in person increased the overall satisfaction of the mentoring rela- tionships. Therefore, the following research propositions are suggested: Research Proposition 1: Mentors will be more willing to engage in e-mentoring when higher presence forms of CMC are incorporated into interac- tions. Research Proposition 2: Mentors will be more sat- isfied with e-mentoring rela- tionships when higher pres- ence forms of CMC are incorporated into interactions.

\section{Discussions and Implications}

E-mentoring as a form of e-learning is rich in possibilities, however much remains to be known regarding attracting and retaining mentors to participate in these types of relationships. Preliminary research indicates that mentoring program designers would be well advised to assess mentors comfort level with various low and high social presence forms of CMC. Technical training on various forms of higher presence forms of CMC could be provided to increase mentors' comfort level. Also, individuals engaged in e-mentoring would be well advised to incorporate high social presence forms of CMC into their interactions with their mentor in order to attain a higher level of satisfaction with the relationship.

In sum, e-learning program designers would be well advised to explore how differences across generations impact CMC prior experience and comfort level. Reverse mentoring programs, in which senior executives are paired with younger entry level employees to learn about social media (Ensher \& Murphy, 2005)[2] could be a tool used to overcome the CMC usage divide. In addition, as users become more comfortable with various forms of CMC, e-mentoring programs can offer a hybrid approach to mentoring program design in which various high and low social presence contexts are incorporated throughout the programs. The millennial generation has different needs and expectation not only for how they learn, but also for how like to receive mentoring (Meister \& Willyerd, 2010)[17]. Therefore, using social presence as a conceptual framework to design blended e-mentoring that provides high and low social presence forms of CMC holds much promise.

\section{REFERENCES}

[1] D. Clutterbuck, "Coaching the team at work," United Kingdom: Intercultural Press, 2007.

[2] E. A. Ensher and Murphy, "Power Mentoring: How Successful Mentors and Protégés Make the Most out of Their Relationships,” Jossey-Bass, San Francisco, California, 2005.

[3] E. A. Ensher and S. E. Murphy, "E-mentoring: Next Generation Research Strategies and Suggestions. In B.R. RAGINS, \& K.E. KRAM (Eds.)," The handbook of mentoring at work: Theory, Research and Practice,2007.

[4] Y. Farbey, “The Global Growth of E-learning,"2013, Available Online at: http://thestartupmagazine.co.uk/index.php/global-growthe-learning/

[5] E. A. Ensher, C. Heun and A. Blanchard, "Online Mentoring and Computer-mediated Communication: New Directions in Research," Journal of Vocational Behavior, 
Vol. 63, No. 2, 2003, pp. 264-288.

$$
\text { doi:10.1016/S0001-8791(03)00044-7 }
$$

[6] P. B. Single, C. B. Muller, C. M. Cunningham, R. M. Single and W. S. Carlsen, "Mentornet-E-mentoring for Women Students in Science and Engineering," Journal of Women and Minorities in Science and Engineering, Vol. 11, No. 3, 2005, pp. 295-309.

$$
\text { doi:10.1615/JWomenMinorScienEng.v11.i3.60 }
$$

[7] S. C. de Janasz, E. A. Ensher and C. Heun, "Virtual Relationships and Real Benefits: Using E-mentoring to Connect Business Students with Practicing Managers,” Mentoring and Tutoring: Partnerships in Learning, Vol. 16, No. 4, 2008, pp. 394-411.

$$
\text { doi:10.1080/13611260802433775 }
$$

[8] M. Higgins and K. Kram, "Reconceptualizing Mentoring at Work: A Developmental Network Perspective," The Academy of Management Review, Vol. 26, No. 2, 2001, pp. 264-288.

[9] S. An and R. Lipscomb, "Instant Mentoring: Sharing Wisdom and Getting Advice Online with E-mentoring," Journal of the American Dietetic Association, Vol. 110, No. 8, 2010, pp. 1150-1155.

[10] J. Headlam-Wells, J. Gosland and J. Craig, “There's Magic in the Web: E-mentoring for Women's Career Development," Career Development International, Vol. 10, No. 6, 2005, pp. 444-459.

\section{doi:10.1108/13620430510620548}

[11] J. Short, E. Williams and B. Christie, "The Social Psychology of Telecommunications," London: John Wiley \& Sons, 1976.

[12] C. M. Harms, "The Effects of Media Type and Personal Relationship on Perceptions of Social Presence," Dissertation Abstracts International, Vol. 65, No. 9, 2005.

[13] J. B. Arbaugh, "Virtual Classroom Characteristics and Student Satisfaction with Internet-based MBA Courses," Journal of Management Education, Vol. 24, No. 32, 2000, pp. 32-53. doi:10.1177/105256290002400104

[14] W. M. Murphy, "From E-mentoring to Blended Mentoring: Increasing Student's Developmental Initiation and Mentors's Satisfaction," Academy of Management Learning \& Education, Vol. 10, No. 4, 2011, pp. 606-622. doi:10.5465/amle.2010.0090

[15] A. Y. Wang and M. H. Newlin, "Online Lectures: Benefits for the Virtual Classroom,” The Journal, Vol. 29, No. 1, 2001, pp. 17-24.

[16] R. Feris, M. A. Gimeno, D. Pinazo, G. Ortet, V. Carrero, M. Sanchiz and I. Ibanez, "Online Chat Rooms: Virtual Spaces of Interaction for Socially Oriented People," Cyberpsychology \& Behavior, Thousand Oaks, CA: Sage.Vol. 5, No. 43-51, 2002, pp. 299-322.

[17] J. D. Meister and K. Willyerd, "Mentoring Millennials," Harvard Business Review, May 2010, pp. 1-4. 